\title{
Incorporating a pediatric concept into tricuspid valve endocarditis: One and a half ventricle repair
}

Shu-Chien Huang, MD, a,b Nai-Hsin Chi, MD, ${ }^{a}$ I-Hui Wu, MD, ${ }^{a}$ Hsi-Yu Yu, MD, ${ }^{a}$

En-Ting Wu, MD, ${ }^{c}$ Shoei-Shen Wang, MD, ${ }^{a}$ Fang-Yue Lin, MD, ${ }^{a}$ and

Yih-Sharng Chen, MD, ${ }^{a}$ Taipei, Taiwan, Republic of China

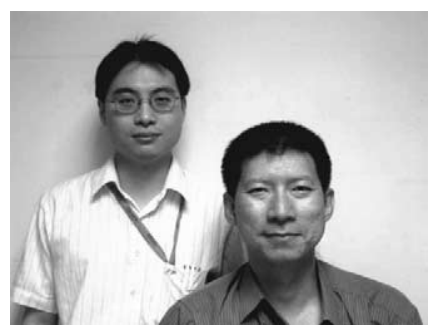

$\mathrm{T}$ ricuspid valve (TV) endocarditis is usually associated with intravenous drug abuse and sometimes with congenital heart disease. Valve repair is the preferred procedure when possible, but extensive infection with valvular destruction would preclude this possibility. TV replacement carries a generally poor long-term prognosis, with debate continuing concerning the choice of a bioprosthetic or mechanical valve. ${ }^{1}$ Valve excision alone is another recommended operation of choice ${ }^{2}$; however, some surgeons experienced a second operation for artificial TV implantation in most instances. We suggested a one and a half ventricle repair procedure for intractable TV endocarditis.

\section{Technique}

Operations were performed during cardiopulmonary bypass and bicaval cannulation, with the superior vena cava (SVC) cannulated at the innominate veins. If all 3 leaflets were impossible to preserve because of the extension of infection, we performed adequate debridement of the infected tissue, including leaflets, chordae, papillary muscles, and sometimes part of the annulus. Several horizontal mattress sutures were placed on the TV annulus of the anterior and posterior leaflet, and therefore the annulus was plicated. The diameter of the TV was reduced to 22 to $26 \mathrm{~mm}$ by using a valve sizer for reference. The $\mathrm{Z}$ value was around -3 or -4 by the body surface area. Then the SVC was amputated at the junction of the right atrium, and the cephalic end of the SVC was anastomosed to the right pulmonary artery as a bidirectional Glenn shunt (Figure 1). The patient was then weaned off cardiopulmonary bypass.

\section{Clinical Data}

We have applied this technique in 4 consecutive patients with intractable TV endocarditis (Table 1) in the past 5 years. All had positive blood cultures and were undergoing combined antibiotic treatment. Three of them underwent operation in urgent condition.

\footnotetext{
From the Departments of Surgery, ${ }^{a}$ Traumatology, ${ }^{b}$ and Pediatrics, ${ }^{\mathrm{c}} \mathrm{Na}-$ tional Taiwan University Hospital, Taipei, Taiwan, Republic of China.

Received for publication July 29, 2005; revisions accepted Aug 4, 2005; accepted for publication Aug 17, 2005.

Address for reprints: Yih-Sharng Chen, MD, Department of Surgery, National Taiwan University Hospital, 7 Chung-Shan S. Rd., Taipei 100, Taiwan (E-mail: yschen11@yahoo.com.tw).

J Thorac Cardiovasc Surg 2006;131:228-9

$0022-5223 / \$ 32.00$

Copyright (C) 2006 by The American Association for Thoracic Surgery doi:10.1016/j.jtcvs.2005.08.046
}

All 3 leaflets were destroyed, except in patient 3, who had part of the posterior valve preserved. After the operation, they all received a full course ( 6 weeks) of antibiotic treatment for specific culture result. The severity of tricuspid regurgitation improved from $4+$ to $2.8 \pm 0.6$, and the functional class also improved from $3.9 \pm 0.3$ to $1.3 \pm 0.3(\mathrm{I}=1$ to $\mathrm{IV}=4)$. Only patient 1 was undergoing diuretic therapy because the marked tricuspid regurgitation persisted postoperatively.

\section{Discussion}

Infected endocarditis at the TV alone is rarely indicated for surgical intervention, except in intractable right-heart failure and huge

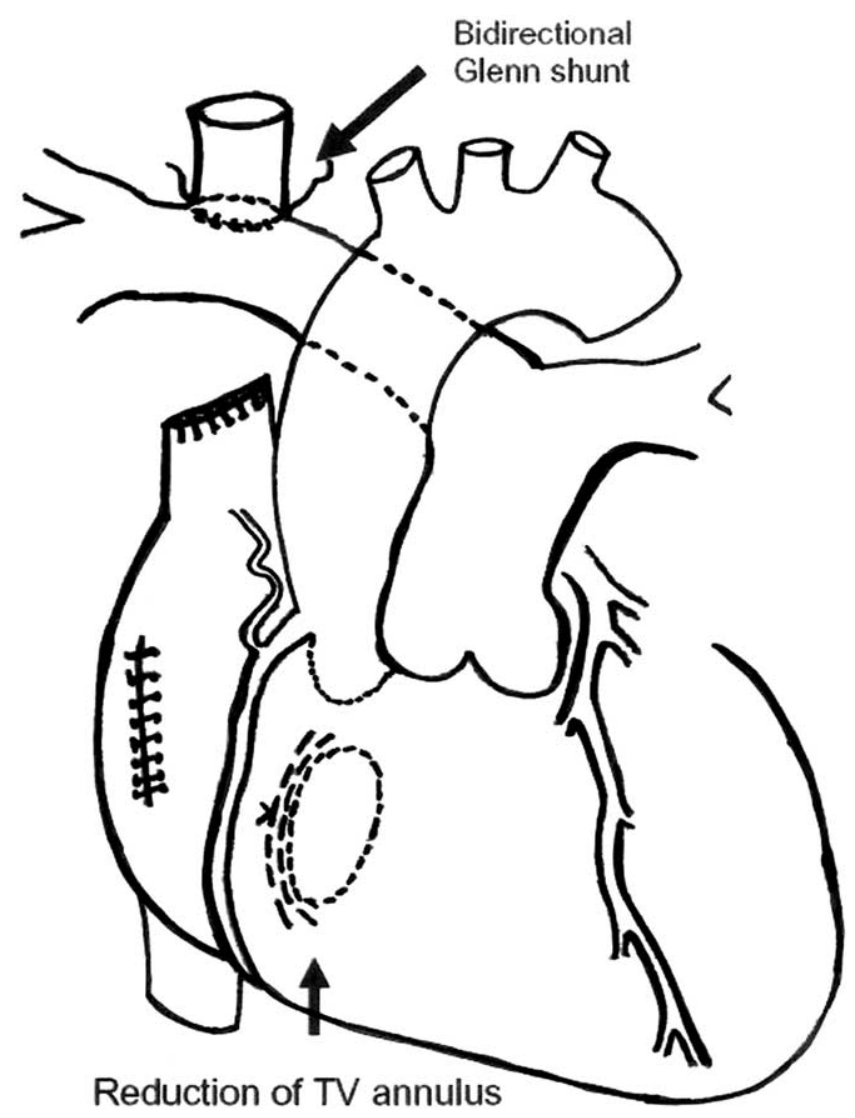

Figure 1. The bidirectional Glenn shunt was performed after excision of the infected tricuspid valve (TV) and reduction of the tricuspid annulus. 
TABLE 1. Clinical data of tricuspid valve endocarditis with one and a half ventricle repair

\begin{tabular}{|c|c|c|c|c|c|c|c|c|}
\hline $\begin{array}{l}\text { Patient } \\
\text { no. }\end{array}$ & $\begin{array}{l}\text { Age } \\
\text { (y) }\end{array}$ & Preoperative status & $\begin{array}{c}\text { Size of } \\
\text { vegetation }\end{array}$ & Involved area & $\begin{array}{l}\text { TR preoperatively } \\
\text { (postoperatively) }\end{array}$ & $\begin{array}{c}\text { Postoperative } \\
\text { SVC (RA) }\end{array}$ & $\begin{array}{l}\text { Functional class } \\
\text { preoperatively } \\
\text { (postoperatively) }\end{array}$ & $\begin{array}{c}\text { Rhythm } \\
\text { preoperatively } \\
\text { (postoperatively) }\end{array}$ \\
\hline 1 & 20 & $\begin{array}{l}\text { Septic shock, } \\
\text { ventilator use, } \\
\text { multiple lung } \\
\text { abscess, } \\
\text { pneumothorax }\end{array}$ & $2.5 \times 2 \mathrm{~cm}$ & 3 leaflets, $P, C, A$ & $4+(3+\sim 4+)$ & $22(12)$ & IV (I II) & $\operatorname{Af}(S)$ \\
\hline 2 & 28 & $\begin{array}{l}\text { Shock, right lower } \\
\text { lobe abscess }\end{array}$ & $3 \times 4 \mathrm{~cm}$ & 3 leaflets, $P, C, A$ & $4+(3+)$ & $20(10)$ & IV (I) & $\operatorname{Af}(S)$ \\
\hline 3 & 22 & $\begin{array}{l}\text { Multiple lung } \\
\text { abscess }\end{array}$ & $3 \times 3 \mathrm{~cm}$ & $\begin{array}{l}2 \text { leaflets } \\
\text { (anterior, } \\
\text { septal), P, C }\end{array}$ & $4+(2+)$ & $18(12)$ & III IV (I) & $S(S)$ \\
\hline 4 & 18 & $\begin{array}{l}\text { Ongoing shock, } \\
\text { right lung } \\
\text { abscess }\end{array}$ & $4 \times 2 \mathrm{~cm}$ & 3 leaflets, $P, C, A$ & $4+(3+)$ & $16(9)$ & IV (I) & $S(S)$ \\
\hline
\end{tabular}

$T R$, Tricuspid regurgitation; SVC/RA, superior vena caval/right atrial pressure 24 hours after the operation (in $\mathrm{mm} \mathrm{Hg}$ ); $P$, papillary muscle; $C$, chordae; $A$, annulus; $3+$, moderate; $4+$, severe; $A f$, atrial fibrillation; $S$, sinus rhythm.

vegetation with ongoing or possible pulmonary embolism. Tricuspid endocarditis is highly associated with drug abuse, which increases the complexity of decision making. Difficulty in discontinuity of drug abuse would increase the incidence of recurrent infected endocarditis in the prosthetic TV. In addition, most of the drug abusers are young, and the bioprosthesis usually degenerates sooner in the younger group than in the aged group. This is the reason why we hesitated to implant bioprostheses in this patient group.

It is reasonable to incorporate the pediatric concept (bidirectional Glenn shunt) in this group with severe regurgitation after total excision of the TV. This one and a half ventricle repair sometimes was applied in congenital heart disease, such as Ebstein anomaly and hypoplastic right hear syndrome. ${ }^{3}$ The bidirectional Glenn procedure diverged SVC flow into the pulmonary artery to provide volume unloading for the right ventricle.

Reduction of the annulus of the TV is also important to reduce regurgitation. For the first case of this protocol (patient 1), we reduced the annulus to $26 \mathrm{~mm}$ ( $\mathrm{Z}$ score of -2 for her), and moderate-to-severe regurgitation was found on postoperative echocardiography. She experienced prolonged intubation and needed oral diuretic therapy. Since then, we reduced the annulus to a $\mathrm{Z}$ size of -3 to -4 or less, and the postoperative course was uneventful for the other 3 patients. In hypoplastic right heart syndrome single ventricular circulation reconstruction was recommended when the $\mathrm{Z}$ value of the TV was less than $-4 .{ }^{4}$ From our experience, the patients seemed to tolerate well when the $Z$ value was -4 or less because the right ventricle size was normal and without diastolic dysfunction in our group (TV endocarditis), and therefore they could tolerate a small TV annulus without signs of tricuspid stenosis.

Our strategy can offer an observational period to ascertain whether the patient abstains from drug abuse. After confirming the patient quit abuse, we can implant the prosthetic valve in the TV if right ventricular failure becomes severe.

In summary, the pediatric concept of one and a half ventricular repair can be successfully applied in the total tricuspid valvulectomy for the intractable tricuspid endocarditis and provides an acceptable hemodynamic condition and several advantageous options for further therapy.

\section{References}

1. Ratnatunga CP, Edwards MB, Dore CJ, Taylor KM. Tricuspid valve replacement: Uk heart valve registry mid-term results comparing mechanical and biological prostheses. Ann Thorac Surg. 1998;66:1940-7.

2. Arbulu A, Holmes RJ, Asfaw I. Surgical treatment of intractable rightsided infective endocarditis in drug addicts: 25 years experience. J Heart Valve Dis. 1993;2:129-37.

3. Kreutzer C, Mayorquim RC, Kreutzer GO, Conejeros W, Roman MI, Vazquez $\mathrm{H}$, et al. Experience with one and a half ventricle repair. J Thorac Cardiovasc Surg. 1999;117:662-8.

4. de Leval M, Bull C, Hopkins R, Rees P, Deanfield J, Taylor JF, et al. Decision making in the definitive repair of the heart with a small right ventricle. Circulation. 1985;72(suppl):II52-60. 